\title{
WADAH AKTIVITAS PENUNJANG KESEJAHTERAAN FISIK DI UJUNG MENTENG
}

\author{
Ivana Setiawan ${ }^{1)}$, Lina Purnama ${ }^{2)}$ \\ 1) Program Studi S1 Arsitektur, Fakultas Teknik, Universitas Tarumanagara, ivana.setiawan97@gmail.com \\ 2) Program Studi S1 Arsitektur, Fakultas Teknik, Universitas Tarumanagara, linapurnama.112@gmail.com
}

\begin{abstract}
Abstrak
Salah satu isu urgensi saat ini adalah belum adanya kesadaran akan gaya hidup yang sehat, gaya hidup tidak sehat dapat berdampak pada kesehatan jangka panjang yaitu resiko pada penyakit tidak menular yaitu Diabetes, Hipertensi, Jantung, dll. Third place sebagai ruang jeda atau ruang santai antara first place (tempat tinggal) dan second place (tempat kerja) saat ini identik dengan tempat berkumpul seperti café, mall, tempat makan, dll yang cenderung kurang mendukung gaya hidup sehat. Sehingga dibutuhkan saat ini adalah Third Place selain sebagai ruang sosial namun juga mengedukasi mengenai pentingnya gaya hidup sehat dan kesejahteraan fisik (physical well-being). Physical Wellbeing adalah Keadaan fisik yang baik bukan hanya karena tidak adanya penyakit tetapi menghindari penyakit dengan makan-makanan bernutrisi, melakukan aktivitas fisik dan memelihara pikiran, dan jiwa yang seimbang (American Association Nurse Anesthetist). Perancangan proyek ini berdasarkan dari isu didapatkan indikator pemilihan tapak terkait dengan teori kualitas lingkungan hidup sekitar yang memengaruhi kesehatan individu (kualitas udara, suhu, penghijauan, dII). Kecamatan Cakung, Jakarta Timur, Kelurahan Ujung Menteng menjadi lokasi yang kurang memenuhi indikator kesehatan kualitas lingkungan hidup. Kawasan ujung menteng merupakan dikelilingi oleh industri dan dekat dengan tempat tinggal namun dekat dengan 3 titik bangunan pendukung seperti olahraga. Aktivitas di dalam proyek terkait dengan program berdasarkan teori Physical Well-being, 5 Ways Of Well-being, dan Third Place dari Ray Oldenburg. Pendekatan pada desain bangunan mengambil pada teori Pattern Language dan Edward T. White buku sumber konsep, yang didasari dari analisa observasi kebiasaan di lingkungan masyarakat sekitar dan data lainnya (makro, mezo, mikro, peraturan pemerintah,dll). Hasil didapatkan adanya potensi dibutuhkan thirdplace yang mendukung kesehatan dan kesejahteraan fisik (Physical Wellbeing).
\end{abstract}

Kata kunci: gaya hidup; kesejahteraan fisik; penyakit tidak menular; third place

\begin{abstract}
One of the issues of urgency now is the lack of awareness of a healthy lifestyle, unhealthy lifestyles can have an impact on long-term health that is the risk of non-communicable diseases namely Diabetes, Hypertension, Heart, etc. The third place as a pause or lounge space between the first place (residence) and second place (work place) is currently connected with places like cafes, malls, places to eat, etc. that do not support a healthy lifestyle. What is needed now is Third Place in addition to social space but also educates about healthy lifestyles and physical well-being. Physical Well-being is a Good Physical Condition Not Only Because It Does Not Ignore Disease by Eating Nutritious Foods, Conducting Physical Activity and Overcoming the Mind, and Balanced Soul (American Association Nurse Anesthetist). The design of this project is based on the issues obtained by site selection indicators related to environmental quality theories that affect individual health (air quality, temperature, greening, etc.). Cakung Subdistrict, East Jakarta, Ujung Menteng Village is a location that does not meet environmental health quality indicators. Menteng tip area is a place that is approved by the industry and close to a place to live but close to 3 points of supporting buildings such as sports. Activities in the project related to the program are based on Physical Welfare theory, 5 Ways of Welfare, and Third Place from Ray Oldenburg. Theory of Language Design and Edward T. White book source concept, which is based on the analysis of observations in the surrounding community environment and other data (macro. Mezo, micro, government regulations, etc.). The results obtained from the potential needed by third parties who support health and physical well-being.
\end{abstract}

Keywords : lifestyle; non-communicable diseases; physical well-being; third place; 


\section{PENDAHULUAN}

\section{Latar Belakang Proyek}

Salah satu isu urgensi saat ini adalah belum adanya kesadaran gaya hidup yang tidak sehat dapat berdampak pada kesehatan di jangka panjang yaitu resiko pada penyakit tidak menular yaitu Diabetes, Hipertensi, Jantung, dll yang biasanya didapatkan pada usia mulai menua akibat gaya hidup tidak sehat di masa muda. Belum adanya kesadaran dapat dilihat dari data bahwa sebagian besar masyarakat Jakarta kurang dalam mengkonsumsi makanan sayur dan buah, dan kurang melakukan aktivitas fisik. Dan juga data lainnya yang terkait berdasarkan teori dari kesehatan.

Physical Well-being adalah Keadaan fisik yang baik bukan hanya karena tidak adanya penyakit. Ini mencakup pilihan perilaku gaya hidup untuk memastikan kesehatan, menghindari penyakit dan kondisi yang dapat dicegah, dan untuk hidup dalam kondisi tubuh, pikiran, dan jiwa yang seimbang (American Association Nurse Anesthetist). Fokus Physical Well-being adalah gaya hidup yang sehat yaitu makan makanan yang sehat, melakukan aktivitas fisik yang menyehatkan. Kegiatan tersebut dapat dekat dengan kehidupan sehari-hari. Maka dengan adanya Third Place dengan tema Physical well-being dapat mengurangi isu kesehatan, resiko penyakit tidak menular.

Salah satu masalah saat ini adalah kurang adanya Third Place yang memberikan manfaat akan kesadaran kesehatan dan kesejahteraan fisik. Dimana Third Place saat ini lebih menekankan terhadap dalam segi komersial, Banyak Third Place seperti Café, Restoran, Taman yang di kelilingi oleh PKL yang cenderung menjual jajanan dan makan tidak sehat bagi Tubuh. Padahal, gaya hidup sehat dapat mempengaruhi kondisi Jasmani dan Spiritual tiap Individu.

\section{Urgensi Isu}

Dengan adanya data di atas bisa kita lihat bahwa gangguan kesehatan yang berujung pada berbagai penyakit yang disebabkan oleh banyak faktor diantaranya adalah gaya hidup (lifestyle) ini adalah penyebab terbesar gangguan kesehatan, prilaku masyarakat yang tidak sehat sperti; 1) kebiasaan merokok, 2) kurangnya kesadaran untuk melakukan aktifitas fisik / olahraga, 3) tidak mampu menangani stres dengan baik, tidak mampu menjaga lingkungan dengan baik, 4) mengonsumsi makanan yang tidak seimbang, (Adisasmito, 2008).

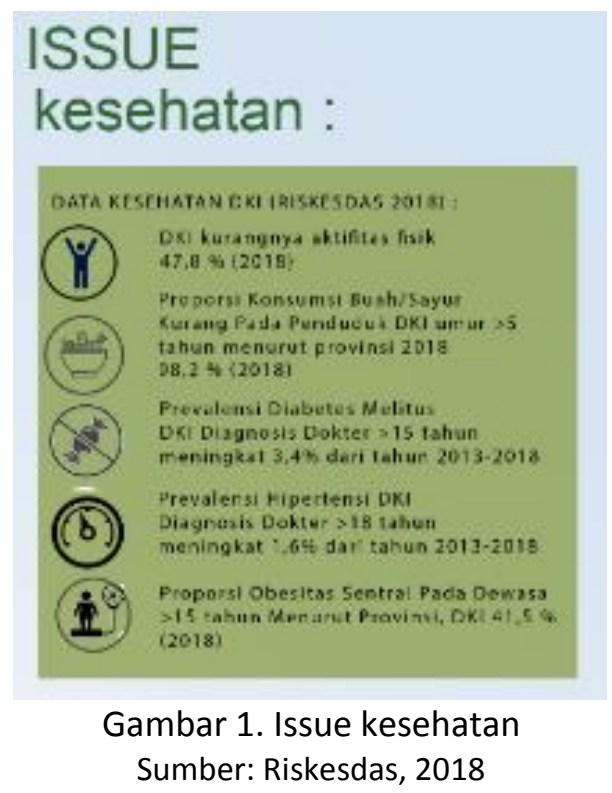

Dari uraian di atas dapat digambarkan banyak penyakit yang disebabkan oleh kurangnya kesadaran akan gaya hidup yang baik,kurang melakukan aktifitas fisik,tidak mampu mengelola emosional,mengonsumsi makanan yang tidak seimbang. 


\section{Pertanyaan Penelitian}

Bagaimana arsitektur dapat berperan dalam mengurangi dari isu kesehatan dan kesejahteraan fisik dari individu dan menampung kebutuhan akan third place dari masyarakat sekitar?

\section{Batasan Masalah}

Batasan masalah terhadap masalah yang ada di lingkungan sekitar dan menghasilkan solusi sebagai tanggapan dari isu gaya hidup tidak sehat yang mempengaruhi kesehatan dan kesejahteraan fisik.

\section{Tujuan Penelitian/Desain}

Mengetahui isu urgensi mengenai kesehatan dan lingkungan yang kurang sehat di sekitar dan mengetahui solusi membuat Third Place yang dapat menjawab isu tersebut

\section{KAJIAN LITERATUR}

\section{Open Architecture}

Open Architecture : a lot to do with empathy (Herman Hertzberger, 2016), menurutnya Open Architecture adalah desain arsitektur berhubungan dengan empati. Ada beberapa fakta bahwa kebanyakan arsitek sibuk dengan struktur bangunan tetapi tidak memperhatikan orang-orang di dalamnya. Sebagian besar arsitek tidak berpikir bagaimana perasaan penggunanya di gedung mereka dan ruang social yang terjadi di dalamnya. Jadi open architecture adalah keterbukaan arsitektur terhadap peran manusia di dalamnya, aktivitas penggunanya yang memainkan peran penting kenapa bangunan itu hidup. manusia akan merasakan dimana ada rasa keterbukaan dan kenyamanan tanpa adanya batas-batas. Biasanya bangunan saat ini lebih memperhatikan apa yang tampak diluarnya saja tapi kurang memperhatikan bagaimana pengalaman perpektif orang di dalamnya.

\section{Third Place}

a. Pengertian The Third Place (The Great Good Place by Ray Oldenburg)

Menurut Oldenburg first place sebagai tempat tinggal dimana seseorang tinggal. Second place adalah tempat bekerja, dimana memungkinkan orang-orang untuk menghabiskan hampir seluruh waktunya. Third place, yang kemudian adalah 'jangkar' dari kehidupan sebuah komunitas yang memfasilitasi dan mendorong interaksi yang lebih luas dan lebih kreatif. Dengan kata lain, "Third place kamu adalah tempat dimana kamu dapat relax di depan umum, dimana kamu berjumpa dengan wajah-wajah yang sudah dikenal dan membuat kenalan baru"

b. Karakteristik The Third Place menurut Ray Oldenburg

Third places adalah tempat bertemu informal dimana orang orang bertemu diantara rumah tinggal dan tempat kerja. Oldenburg mendeskripsikan melalui karakteristik.

- On Neutral Ground (Lokasi yang netral), Pengunjung dari third place tidak terikat dengan peraturan yang mewajibkan mereka berada disana. Mereka tidak terikat dengan daerah secara finansial, politik, hukum, atau sebaliknya bebas untuk datang dan pergi sesuka mereka.

- The Third Place as Leveler (penyamarataan tidak memandang pengkatergorikan berdasarkan umur, kelas, dan ideogi lainnya), Third places tidak menempatkan status individu di komunitas. Ekonomi atau status social seseorang tidaklah terlalu penting di dalam third place, memungkinkan rasa kesamaan diantara penghuninya. Tidak ada prasyarat atau persyaratan yang mencegah penerimaan atau partisipasi di third place.

- Conversation is the Main Activity, Obrolan yang menyenangkan dan membahagiakan adalah focus utama dari aktivitas di Third Place, meskipun tidak harus menjadi satu-satunya aktivitas. Nada dari percakapan yang biasanya ringan dan lucu, cerdas dan sifatnya mainmain justru sangat dihargai.

- Accesibility and Acccommodation (Aksesibilitas dan Akomodasi), Third places haruslah 
terbuka dan mudah untuk diakses oleh mereka yang menggunakannya. Mereka juga harus akomodatif, yang artinya memenuhi kebutuhan penghuninya, dan semua penghuni merasa bahwa kebutuhan mereka telah terpenuhi.

- The Regulars (Pengunjung yang tetap), Third places memiliki sejumlah regular (pengunjung tetap) yang membantu memberikan ruang nada, dan membantu mengatur mood dan karakteristik daerah. Reguler ke third place juga menarik newcomers (pendatang baru), dan membantu mereka ke space (ruang) merasa diterima dan ditampung.

- A Low Profile (tempat yang sederhana), Third places secara karakteristik sehat adalah tanpa pemborosan atau merasa henat, dan memiliki sifat yang sederhana. Third places tidak pernah sombong atau sok, dan menerima semua jenis individu dari berbagai lapisan masyarakat.

- The Mood is Playful (Mood yang menyenangkan), Tone dari percakapan di third places tidak pernah ditandai dengan ketegangan atau permusuhan. Sebaliknya, third places memiliki suasana alami yang menyenangkan, dimana percakapan yang cerdas dan sembrono tidak hanya umum, tetapi sangat dihargai.

- A home Away From Home (Rumah yang jauh dari Rumah tinggal): Penghuni dari third places akan sering memiliki perasaan yang hangat, kepunyaan, dan kepemilikan yang sama seperti rumah mereka sendiri. Mereka akan merasa seperti memiliki sepotong diri mereka yang tertanam di dalam space, dan mendapatkan pemulihan secara spiritual dengan menghabiskan waktu disana.

\section{Kesehatan (Health)}

a. Pengertian Kesehatan

Organisasi kesehatan dunia WHO (The World Health Organization) mendefinisikan kesehatan bukan hanya keadaan fisik yang baik tetapi merupakan "keadaan fisik yang baik tetapi juga mencangkup keadaan mental dan sosial yang baik". Definisi kesehatan telah berubah, sekarang lebih mencangkup hubungan timbal balik antara faktor sosial, psikologis, serta medis. Kesehatan bukan lagi sekedar masalah akses ke perawatan medis tetapi ditentukan oleh sejumlah faktor yang terkait dengan kualitas lingkungan binaan kita atau lingkungan sekitar kita (CABE. (2009). Sustainable places for health and Well-being. London: Commission for Architecture and the Built Environment).

Gaya hidup yang sehat di tempat tinggal maupun di komunitas adalah cara untuk mengurangi penduduk yang meningkat pada layanan kesehatan. Dengan demikian merancang rumah, lingkungan dan lingkungan kerja untuk meningkatkan kesehatan dan kesejahteraan adalah peluang kehidupan yang lebih baik.

Kualitas binaan atau lingkungan sekitar kita merupakan keadaan individu yang sehat dipengaruhi lingkungan yang sehat. Lingkungan sehat yang dimaksud individu dapat merasakan kenyamanan adaptif yang dipahami secara luas sebagai "kondisi pikiran yang mengekspresikan kepuasan terkait lingkungan seperti termal, suhu, visual,dll dengan indikator kualitas udara, suhu, kecepatan angin yang nyaman, visual ruang terbuka hijau untuk vegetasi, dll. (ISO. 2005.7730:2005 - Ergonomics of the thermal environment. Internation Organization For Standartdization)

\section{Well-being (Kesehatan dan Kesejahteraan)}

\section{a. Pengertian Kesehatan dan Kesejahteraan (Well-being)}

Pengertian dari kesehatan dan kesejahteraan adalah kesejahteraan mental atau kebahagiaan. Sebagai contoh, di bidang kenyamanan termal telah terjadi pengembangan dari teori kenyamanan fisiologis yang berdasarkan karya Mani Fanger, ke pemahaman yang lebih holistik yang mengarah pada adopsi teori kenyamanan adaptif. Menurut penelitian mengenai kesehatan telah diperluas dari pengobatan fisik lebih luas menjadi lebih holistik terhadap kesejahteraan per individu di populasi. Ini adalah topik kesejahteraan yang merupakan fokus utama dari jurnal ini. 
Gagasan kesejahteraan terdiri dari dua elemen kunci: merasa baik dan berfungsi dengan baik. Perasaan bahagia, keingintahuan, dan keterlibatan adalah ciri khas seseorang dengan perasaan positif tentang diri mereka sendiri. Memiliki hubungan positif, kontrol atas hidup Anda sendiri dan tujuan adalah semua atribut berfungsi dengan baik.

\section{b. Respon Konsep Desain dan kesejahteraan (Five ways to Well-being)}

Penelitian terbaru telah menunjukkan hubungan karakteristik desain fisik utama dengan Five Ways to Well-Being (Hubungan Connect, Tetap Aktif Keep Active, Perhatikan Take Notice, Terus Belajar Keep study dan Berikan Give), yang telah dikaitkan dengan kesehatan mental yang positif .Ini mendukung teori dan penelitian saat ini, yang menunjukkan bahwa kuantitas dan kualitas yang memadai dari beragam sumber daya lingkungan, sosial dan fisik dapat memengaruhi kondisi manusia, yang, pada akhirnya, dapat meningkatkan perilaku sehat populasi yang lebih luas.

- Connect : keterhubungan kuantitas dan kualitas hubungan sosial (misalnya berbicara dan mendengarkan keluarga atau orang asing) berkorelasi dengan kesejahteraan yang dilaporkan serta kesehatan fisik. (desain Penyediaan 'ruang publik sehari-hari' lokal menciptakan peluang bagi orang untuk terhubung, dan merupakan sumber daya kesejahteraan yang signifikan bagi individu dan masyarakat luas)

- Keep Active : ada banyak bukti dari studi global dan meta untuk menunjukkan bahwa aktivitas fisik mengurangi gejala mental dan kesehatan fisik (Karakteristik desain yang terkait dengan peningkatan aktivitas mencakup akses ke fasilitas aktivitas fisik (mis. Pusat olahraga dan peralatan)

- Take Notice : menjadi penuh perhatian - memperhatikan masa kini dan menyadari pikiran dan perasaan - adalah perilaku yang mengurangi gejala stres, kecemasan dan depresi. (penyediaan seni, taman dan landscape mengalihkan perhatian dari kecemasan dan masalah yang dilalui lebih memperhatikan ke alam taman sekitar)

- Keep Learning : aspirasi dibentuk di awal kehidupan, dan mereka yang memiliki aspirasi lebih tinggi cenderung memiliki hasil yang lebih baik. Aspirasi semacam itu dimodifikasi oleh lingkungan. Bukti menunjukkan bahwa, juga di kemudian hari, mereka yang berpartisipasi dalam kelas musik, seni, dan malam, misalnya, mencapai kesejahteraan subjektif yang lebih tinggi. (Ada bukti dari penelitian pendidikan bahwa lingkungan fisik rumah dan ruang kelas menengahi variabel yang mempengaruhi perkembangan intelektual)

- Give : bukti telah muncul bahwa perilaku pro-sosial daripada egois memiliki dampak positif pada kebahagiaan. Konsekuensi semacam itu dari perilaku altruistik terkait dengan pengeluaran untuk orang lain yang bertentangan dengan diri sendiri dan melalui sukarelawan dan menawarkan bantuan. (Kehadiran stresor lingkungan mengurangi perilaku membantu, tetapi sedikit bukti eksplisit lebih lanjut tersedia di luar apa yang telah dibahas di atas, yang menghubungkan lingkungan fisik dengan modal sosial lingkungan).

\section{Physical Well-being (Kesejahteraan Fisik)}

Stanley D. (2014) menyatakan bahwa untuk mencapai kesehatan atau prilaku hidup sehat ada tujuh dimensi yang saling terkait dan ketergantungan yang dimiliki harus dimiliki oleh setiap individu yaitu: Social Well-being, phyisical Well-being, emosional Well-being, career Well-being, intelektual well-being, enviromental Well-being, spritual well-being.

Dengan melihat fakta tersebut dibutuhkan usaha untuk memperbaiki permasalahan yang berkaitan dengan gangguan kesehatan, dari ketujuh komponen well-being, peneliti membatasi penelitian ini hanya pada physical wellbeing,dengan alasan waktu penelitian yang singkat, sehingga tidak semua komponen well-being dapat diteliti.

Physical Well-being adalah kemampuan seseorang dalam melakukan aktivitas sehari-hari, pencapaian kehehatan, memelihara nutrisi secara adekuat dan berat badan ideal, terhindar dari ketergantungan obat dan alkohol atau rokok serta secara umum melakukan kebiasan hidup 
positif (Kant, 2014). Dalam penelitian Kant 2014 menyatakan bahwa penerapan Physical Wellbeing dapat mengurangi resiko terjadinya penyakit seperti: hipertensi, penyakit jantung koroner, kangker payudara, depresi, penyakit kerena gangguan tulang, diabetes militus.

\section{METODE}

Metode penelitian dari pengambilan data data referensi dari data pemerintah, Studi preseden, survey lapangan, buku, artikel dan jurnal dari internet. Desain dimulai dari isu yang kemudian mendapatkan kriteria yang diperlukan dalam memilih tapak, yang berakar pada teori dan buku dalam menentukan isu dari tapak, kemudian analisa lingkungan sekitar potensi Third Place pada lingkungan sekitar dengan teori Third Place Ray Oldenburg dan teori Well-being yang menghasilkan program berdasarkan studi preseden dan teori untuk mengurangi isu masalah. Pendekatan pada desain bangunan mengambil pada Teori Pattern Language dan Edward T.White buku sumber konsep, dan analisa makro, mezo, mikro, dan data lainnya.

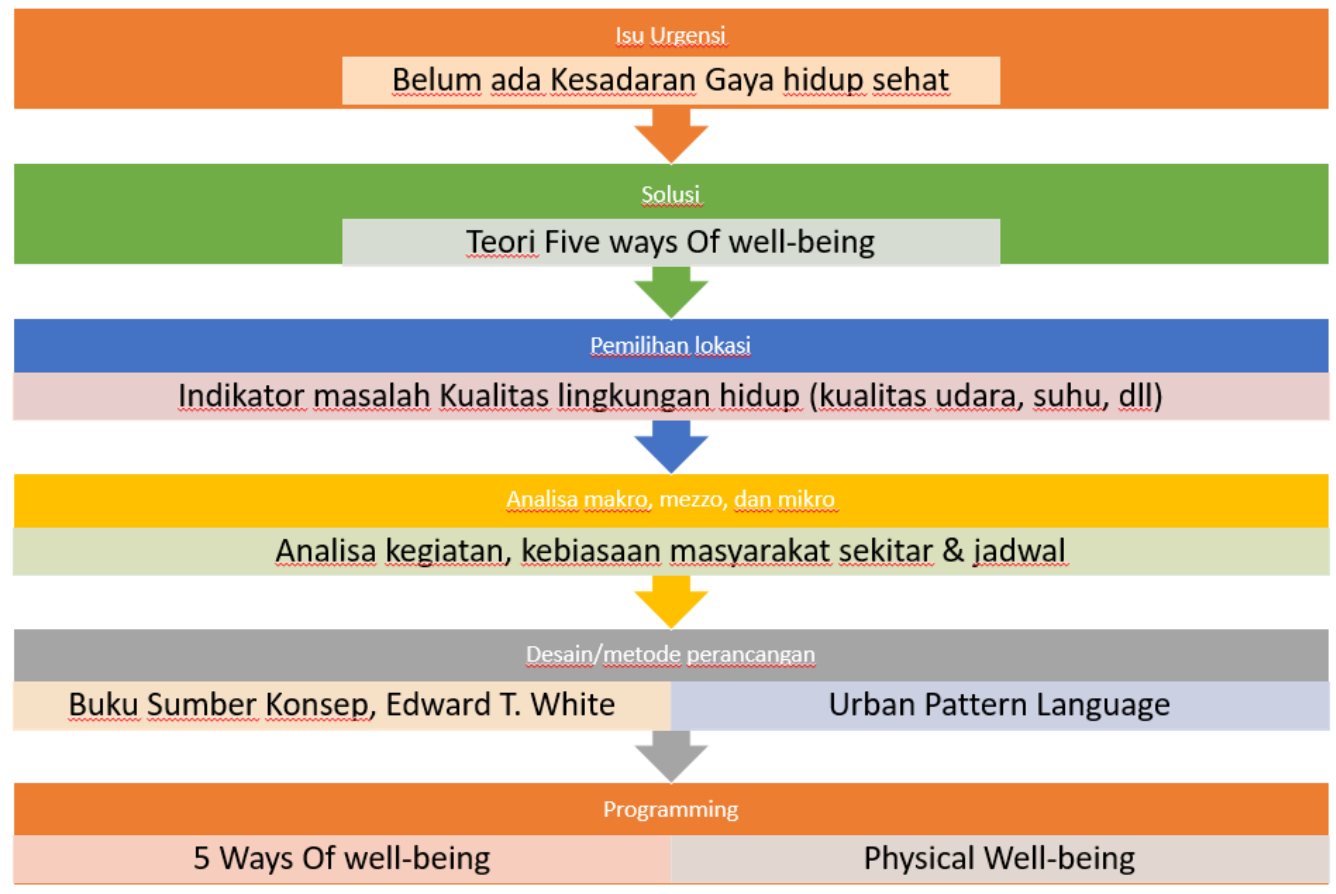

Gambar 2. Kerangka berpikir

Sumber: Penulis, 2019

\section{DISKUSI DAN HASIL}

Metode penelitian dari pengambilan data data referensi dari data pemerintah, Studi preseden, survey lapangan, buku, artikel dan jurnal dari internet. Desain dimulai dari isu yang kemudian mendapatkan kriteria yang diperlukan dalam memilih tapak, yang berakar pada teori dan buku dalam menentukan isu dari tapak, kemudian analisa lingkungan sekitar postensi Third Place pada lingkungan sekitar dengan teori Third Place Ray Oldenburg dan teori Well-being yang menghasilkan program berdasarkan studi preseden dan teori untuk mengurangi isu masalah. Pendekatan pada desain bangunan mengambil pada Teori Pattern Language dan Edward T.White buku sumber konsep, dan analisa makro, mezo, mikro, dan data lainnya.

\section{a. Analisa Tapak}

Site dipilih merupakan hasil dari analisa data berdasarkan isu masalah kesehatan,Kecamatan Cakung Jakarta Timur Kelurahan Ujung Menteng menjadi lokasi yang kurang memenuhi indikator kesehatan lingkungan. Kawasan ujung menteng merupakan lokasi industri dekat dengan tempat tinggal (First Place) namun dekat dengan 3 titik bangunan pendukung seperti olahraga. Ada potensi ketertarikan terhadap kesehatan fisik. Lokasi $500 \mathrm{~m}$ dari jalan primer 

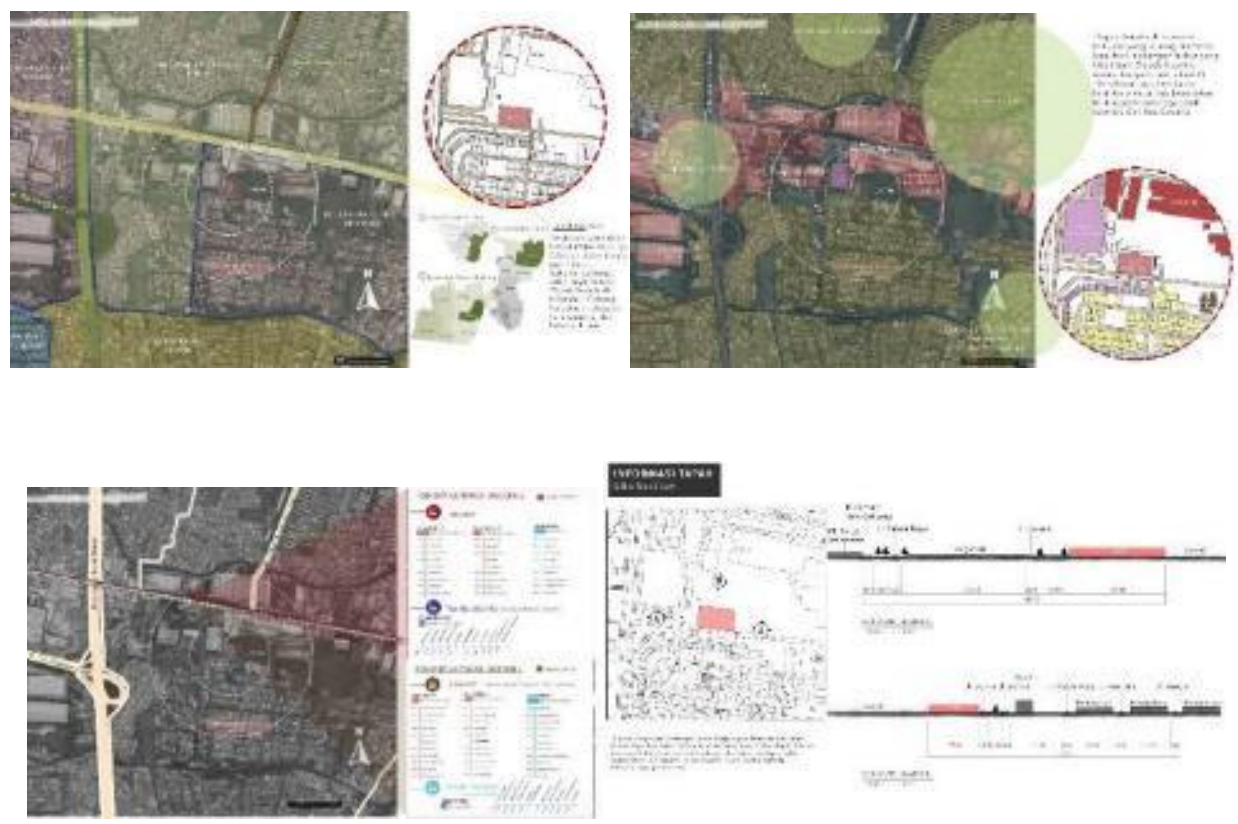

Gambar 3. Analisa Makro, Mezo, dan Mikro Sumber: Penulis, 2019
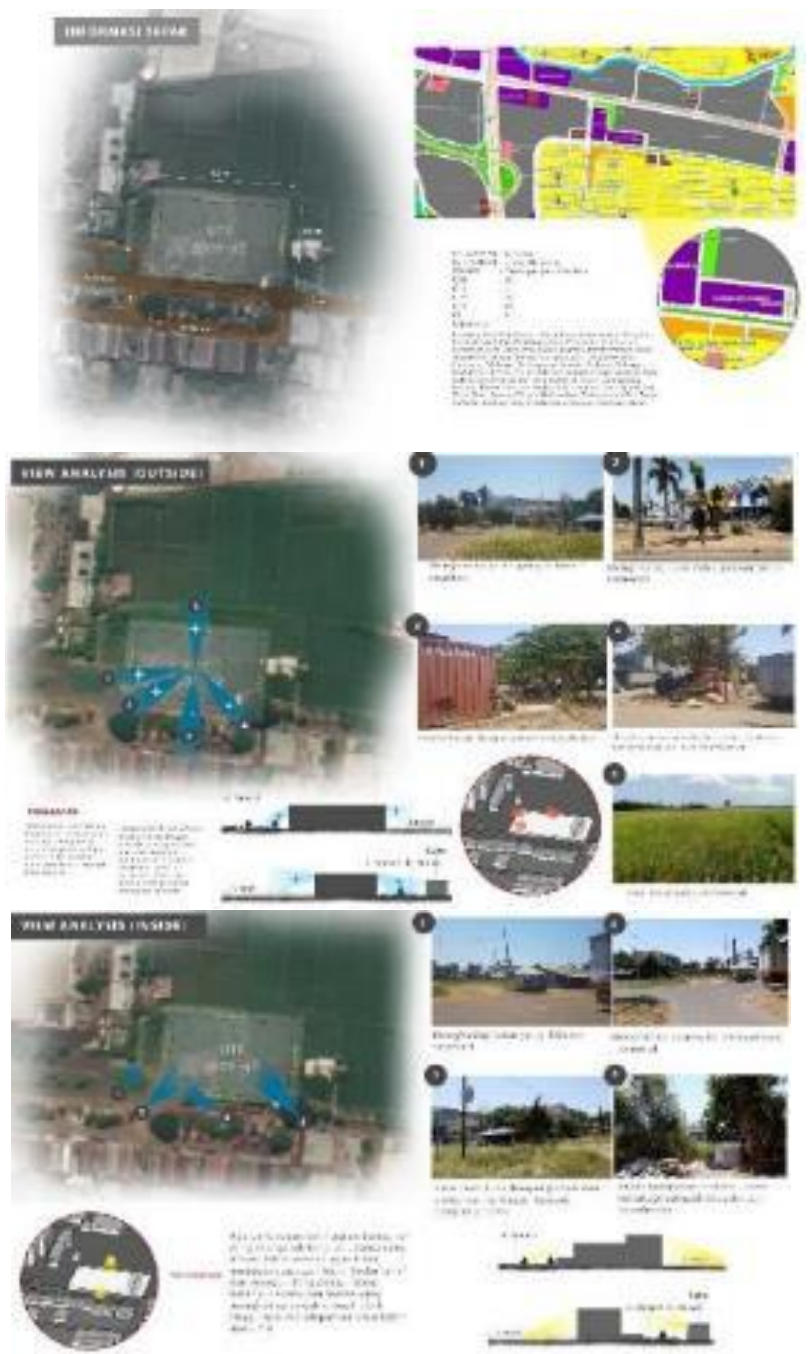

Gambar 4. Data Informasi Tapak

Sumber: Penulis, 2019 
Tapak Berada di Zonasi Perindustrian dan Jasa (First Place), dan pemukiman (Second Place), dikelingi ruko dan perkantoran 2-4 LT. Zonasi tapak merupakan Perdagangan dan jasa yang diizinkan salah satunya untuk Gelanggang olahraga yang merupakan aktivitas fisik kriteria Physical Well-being.

$\begin{array}{ll}\text { KECAMATAN : Cakung } \\ \text { KELUHAHAN : Ujung Menteng } \\ \text { ZONASI } & \text { Perdagangan dan tesa } \\ \text { KDS } & 50 \\ \text { KLE } & -2 \\ \text { KDH } & : 30 \\ \text { KTE } & : 55 \\ \text { KB } & : 4 \\ \text { Dilizinkan: } & \end{array}$

Katwing, Bits Porjalanan, , Fianet den Gams Conter, Fangkas Rambut dan Solon. Penitipan Anak, Pencucjan Kesedaran

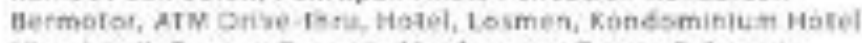

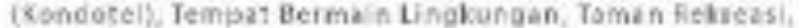
Lapangan Olahraga, Gelanggang Remaja, Gedung Osahraga.

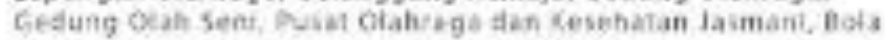
Gellinding reowfiag) dan Eole Sodea (Billiard), Gelanggase? Renang, Taman Hiburaa, Stuelio Ketesampilar, Panti Mandi Uap. Grik a Pijat, Spa-da n Fitnes, K at malam, Disketek dan Bar, Teatre? Terbuka, Bieikeps, Musil Hideo dan Karacke, Restoran, Pewat

Gambar 5. Ketentuan Peraturan Zonasi Sumber: Zonasi DKI Jakarta (https://jakartasatu.jakarta.go.id)

Tapak berada dekat dengan ruko yang berfungsi sebagai perkantoran, Komersil, Gereja, Industri dan dekat dengan pemukiman Perumahan Modern, terdapat bangunan pendukung pendidikan SD Sang Timur Cakung. Di sekitar tapak terdapat aktivitas Third Place seperti berkumpul di warung, berteduh di pohon, bermain basket di parkiran ruko, dan berkumpul di gazebo bambu.

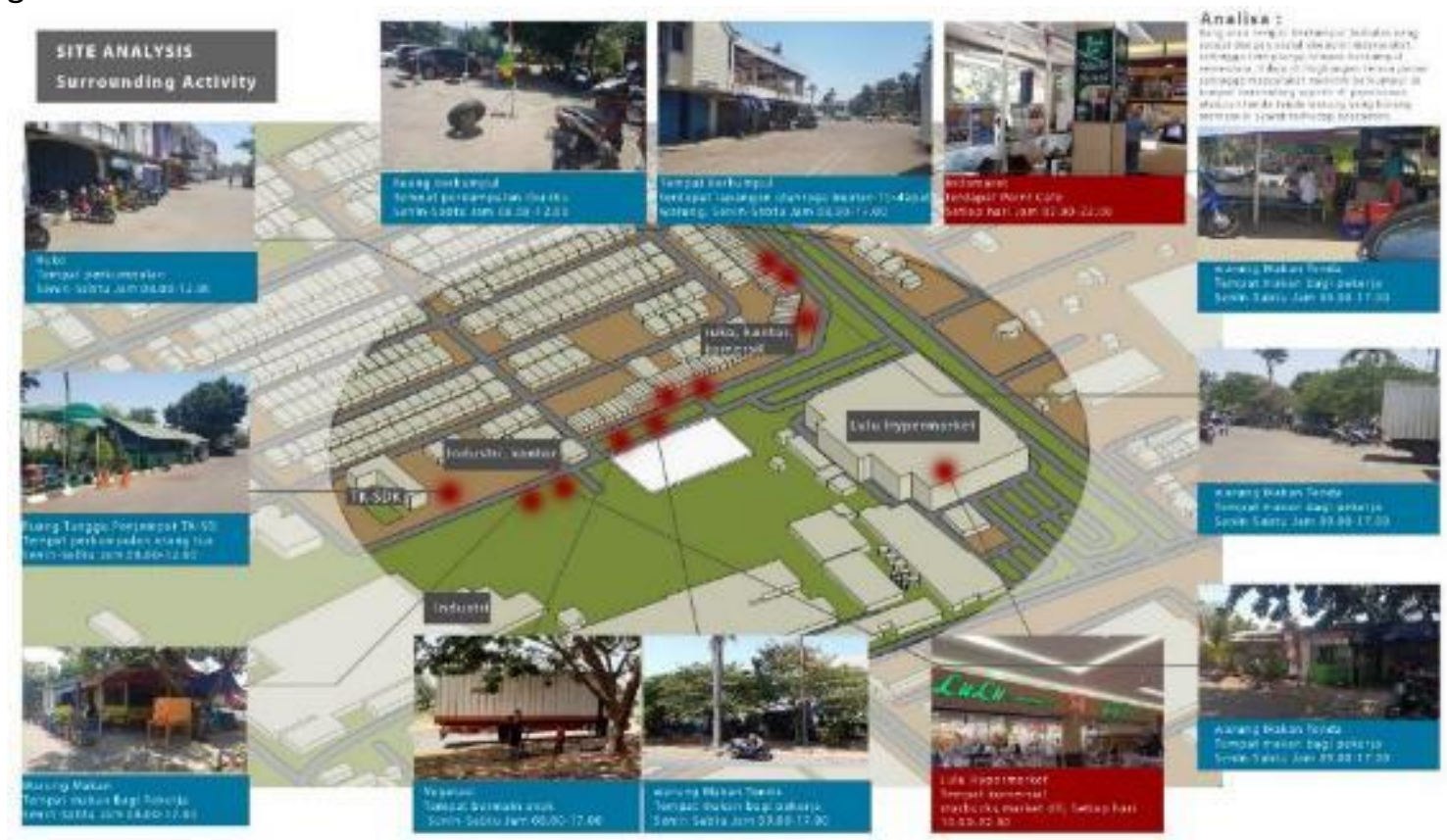

Gambar 6. Analisa Surrounding Activity

Sumber: Penulis, 2019 


\section{b. Program}

Program didapat dari Analisis Surrounding Activity sekitar tapak dan Teori Program Physical Well-being dari AANA (American Association of Nurse Anesthetics) dan Buku 5 Ways of Wellbeing dari Ruben S Seetharamdo, Ph.D , Mind Charity UK, dan Studi Preseden didapatkan program sebagai berikut:
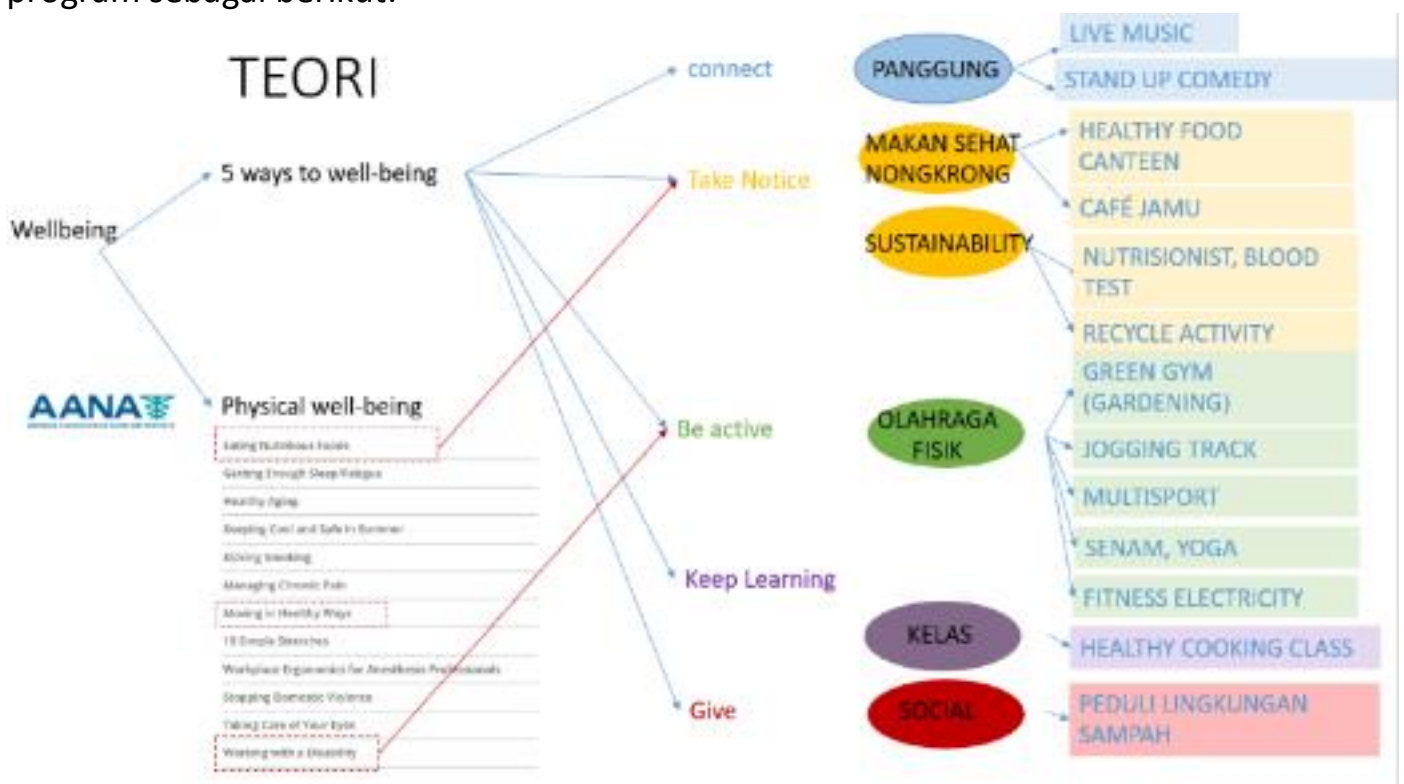

Gambar 7. Analisa Program Physical Well-being Sumber: Penulis, 2019

\section{c. Konsep dan Bentuk Rancangan}

Karakteristik Third Place pada Kawasan terbentuk dari Analisa Surrounding Activity membentuk kata kunci sebagai berikut:
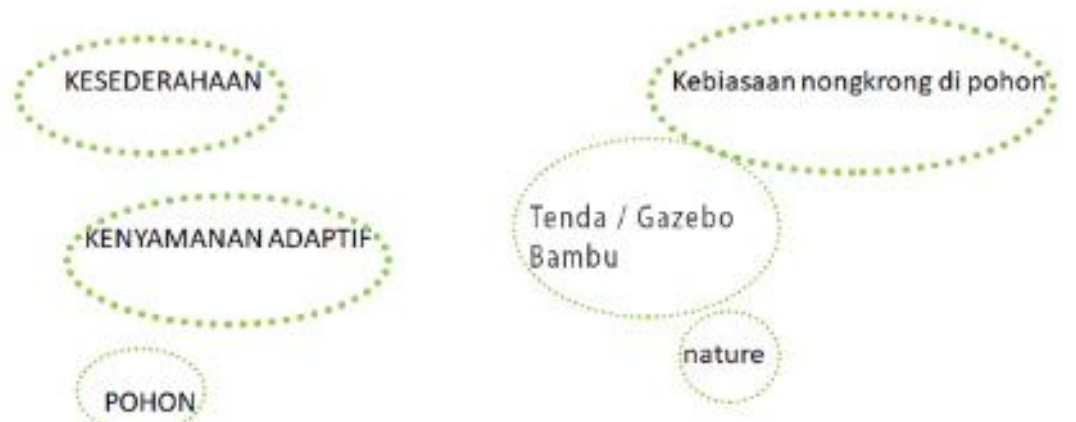

Gambar 8. Konsep dan Bentuk Rancangan

Sumber: Penulis, 2019

\section{Bentukan Massa}

Bentukan massa berdasarkan analisa lingkungan sekitar yang cenderung kurang memiliki view kurang menarik karena wilayah tercemari oleh sampah plastik dan merupakan kawasan yang panas dan penuh debu dan pasir. Maka di bangunan terdapat court sebagai vegetasi dan area berkumpul yang berada di tengah sebagai penghubung program aktivitas di bangunan. Berdasarkan Teori Buku Urban Pattern Language mengenai Hierarchy Of Open Space, orangorang cenderung mencari bukaan yang besar di depan mereka (hal.114), Courtyards Which Live (hal.115) Courtyard terbuka dan harus bisa dilewati semua orang, Courtyard mempunyai koneksi yang kuat dengan ruang lainnya, Courtyard dekat dengan massa sekitarnya, Courtyard merupakan ruang besar. Activity Pockets, memasukan aktivitas di Public space seperti tempat duduk, taman, komersial,dll (hal.124). 

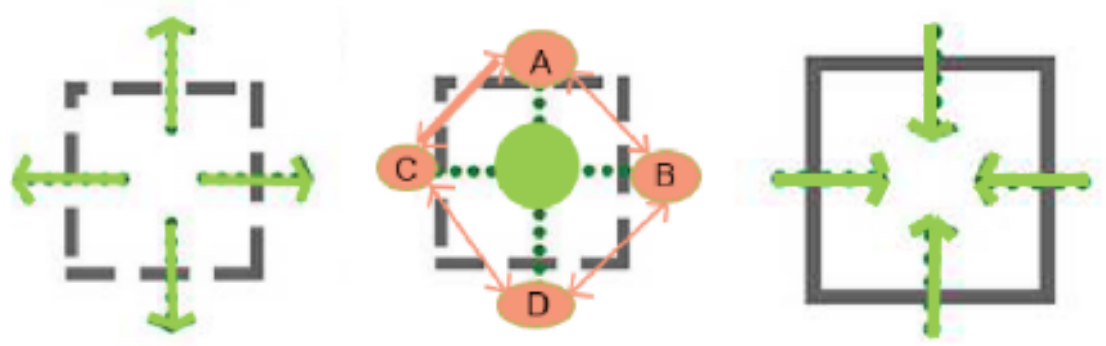

Gambar 9. Diagram ilustrasi Teori Urban Pattern Language

Sumber: Penulis, 2019

Konsep Bentukan massa bangunan mengikuti Edward. $T$.white yaitu ada massa yang dipindahkan untuk memberikan ruang yang berbeda agar tidak massive dan monoton. Kegunaan massa bangunan sebagai penanda Entrance bagi pejalan kaki untuk memberikan visualisasi bangunan lebih baik. Agar ada perbedaan entrance menuju Lobby atau langsung menaiki tangga yang dekat dengan parkir sepeda.

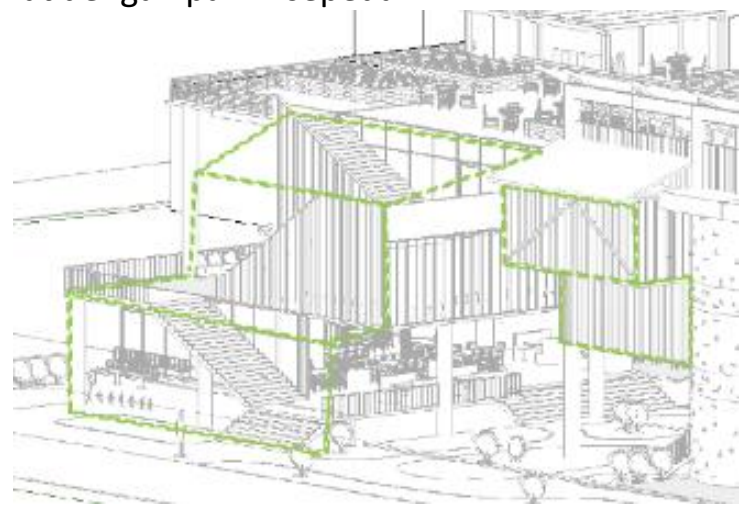

Gambar 10. Bentukan 3D Bangunan

Sumber: Penulis, 2019

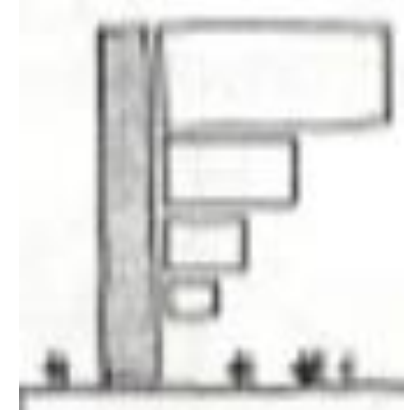

Gambar 11. Potongan Edward T.White Sumber: Penulis, 2019

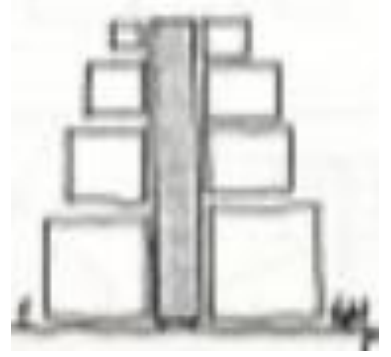

Gambar 2. Potongan Edward T.white Sumber: Penulis, 2019 
Pada Gambar 7. pada bangunan digunakan sebagai entrance pejalan kaki masuk untuk menandai area Lobby. Pada Gambar 8. Pada bangunan digunakan untuk sirkulasi tangga menuju ke fasilitas penting seperti gym, healhty canteen, café jamu, dan taman Rooftop.

3.

1.

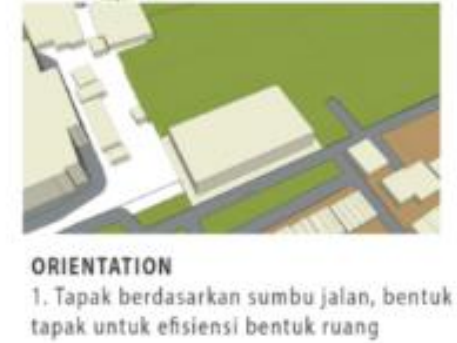

3.

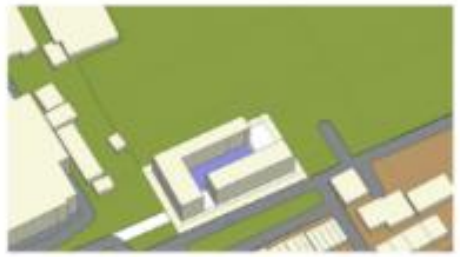

SUBSTRACTION

1. Mengurangi massa sebagai area sirkulasi masuk langsung ke taman, sebagian untuk lapangan multisport.

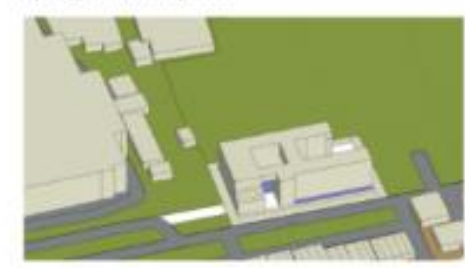

\section{SUBSTRACTION}

1.Mengurangi kemasifan, sebagai area welcoming bagi pedestrian.

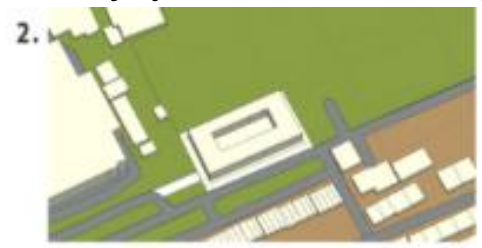

SUBSTRACTION

1. Pembentukan taman court di dalam sebagai tempat ruang bertemu. furban Pattern Languange.

2. Respon dari daerah industri kebisingan, debu, pasir, dari sampah industri dan panas matahari.

4.

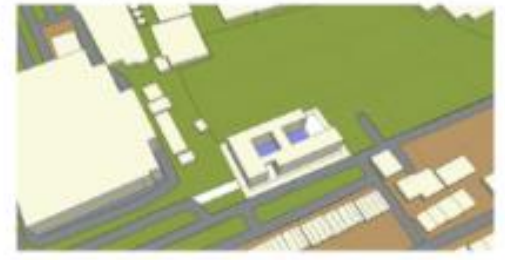

\section{CONNECTION}

1. Menyambungkan massa, mengkaitkan program satu sama lain.

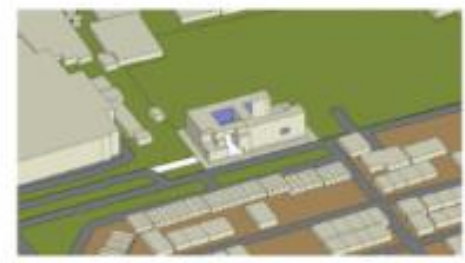

\section{ADDITION}

1.Permainan Maju mundur pada massing

mengurangi kemasifan, agar cahaya

ventilasi dapat masuk ke bangunan dan

bentuk unik. (Edwatd T. White)
Gambar

Proses

Gubahan Massa

Sumber: Penulis, 2019

\section{Second Skin dan dinding}

Inspirasi dari kesederhanaan gazebo bambu yang terdapat di sekitaran tapak sebagai area berkumpul. Selain itu bambu juga baik untuk sirkulasi udara, mengutip dari kriteria dari Kenyamanan Adaptif.

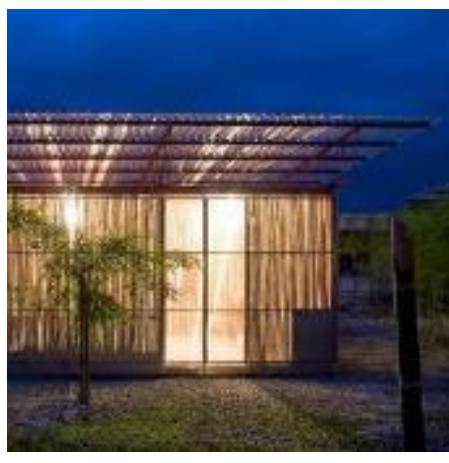

Gambar 14. Contoh Gazebo Bambu Sumber: Jepara Furniture, 2016

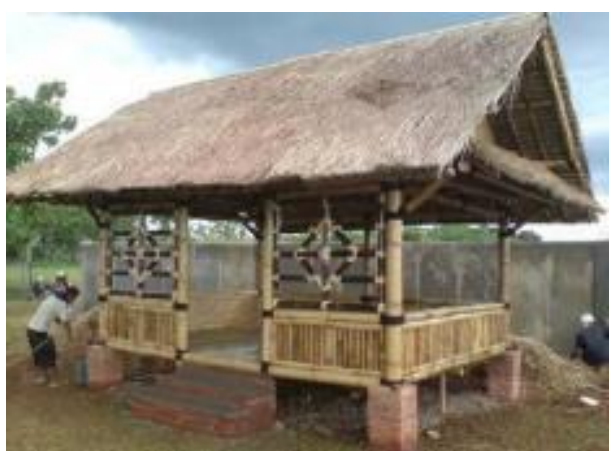

Gambar 15. Referensi facade Low Cost House Sumber : Vo Trong Nghia Architects 


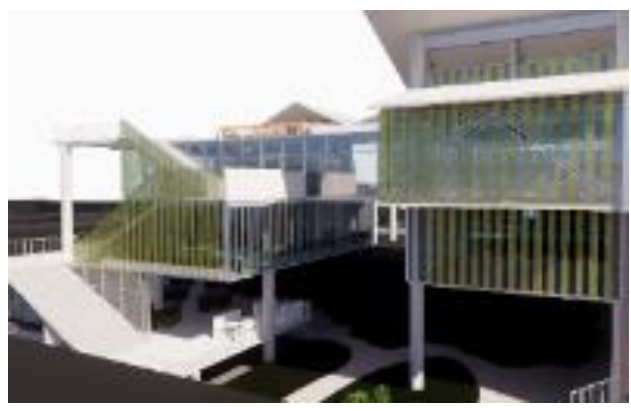

Gambar 16. 3D Facade bangunan bagian depan

Sumber: Penulis, 2019

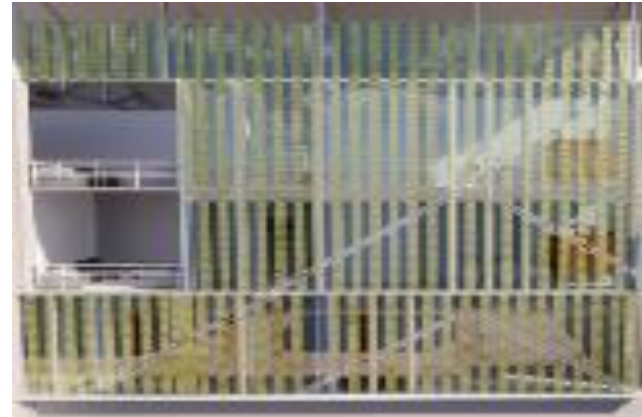

Gambar 17. Fasad Bambu Tampak Depan bangunan

Sumber: Penulis, 2019

Fasad dengan ukiran geometris segitiga terinspirasi dari bentukan gazebo bamboo yang melambangkan bentukan kesederhanaan atap gazebo yang sebagai 'ruang tamu' bagi mereka, berdasarkan familiarity terhadap Third Place di sekitar tapak yang cenderung sederhana.

\section{KESIMPULAN DAN SARAN}

\section{Kesimpulan:}

a. Berdasarkan data-data yang ada mengenai kesadaran akan gaya hidup masih kurang, baik dari data-data yang ada, masih banyak yang kurang sadar akan kesehatan fisik dan jumlah pederita penyakit menular (Hipertensi, Kolestrol, diabetes, dll) yang terus bertambah tiap tahun.

b. Solusi dari isu kesehatan fisik adalah menjalankan dari program Physical Well-being yaitu makanmakanan bernutrisi, melakukan olahraga fisik, dan kesejahteraan secara jiwa. Dan juga teori dari 5 ways of Well-being tentang kesejahteraan individu dengan lingkungan sekitarnya. Yang kemudian menjadi sebuah program dan dikombinasikan dengan kebiasaan dari masyarakat sekitar.

c. Third Place tidak jauh dari kesibukan suatu wilayah terlebih bagi yang memiliki jadwal padat seperti para pekerja industri yang membutuhkan tempat berteduh dan bersantai disela-sela kesibukannya. Terlebih dengan mengandalkan 8 kategori syarat Third Place dari Ray Oldenburg membuat third place yang dapat diterima semua kalangan, baik dari ekonomi golongan rendah sampai seterusnya. Kemudian, dapat menjadi solusi dari isu yang ada disekitar.

d. Cara menentukan lokasi yang berkesinambungan dengan isu kesehatan individu dengan lingkungan sekitarnya, yaitu dengan indikator kualitas lingkungan hidup (kualitas udara, suhu, penghijauan, kenyamanan adaptif, dll). Di dapatkan Jakarta Timur, kecamatan Cakung, Kelurahan Ujung Menteng. Lokasi tersebut kurang memenuhi kriteria kualitas lingkungan hidup yang baik baik dari kesadaran masyarakat akan kesehatan fisik, kualitas udara tidak baik, sebagian besar wilayah $30 \%$ nya adalah industri, dll.

e. Desain dari bangunan dari tipologi dengan bangunan sekitar yang sederhana, konsep dari bamboo yang menjadi elemen arsitektur. Desain mengadaptasi dari teori dari Edward T. White yaitu buku sumber konsep dan teori Urban Pattern Language mengadaptasi adanya activity pocket yang memberi ruang publik yang berkesinambungan dengan ruang lainnya.

Saran:

Penulis menyarankan untuk mengadaptasi konsep dari Third Place yang dapat diterima oleh masyarakat sekitar tanpa membeda-bedakan orang dari golongan manapun, dan bahwa rancangan apapun pada dasarnya memperhatikan tingkah laku, kebiasaan dari manusia yang menggunakan ruang tersebut. Dengan adanya third place dapat menjadi ruang jeda yang memberikan kesempatan interaksi baik secara langsung maupun tidak langsung kepada orang lain ataupun sesamanya. 


\section{REFERENSI}

Adisasmito, D. W. (2008). Analisis Tingkat Keseriusan Pemerintah Provinsi DKI Jakarta dalam Memberlakukan Larangan Merokok di Tempat Umum. Depok: Fakultas Kesehatan Masyarakat Universitas Indonesia.

Alexander, C. (1977). A pattern language: towns, buildings, construction. Oxford university press.

CABE. (2009). Sustainable places for health and Well-being. London: Commission for Architecture and the Built Environment.

Dan C., R. N., et.al (2012). Stress: perceptions, manifestations, and coping mechanisms of student registered nurse anesthetists. AANA (American Association of Nurse Anesthetists) journal, 80(4), S49.

Dyer, E., (2016), Interview with Herman Hertzberger, Architecture and Education, diunduh 23 Januari 2020, dari https://architectureandeducation.org/2016/02/03/interview-withherman-hertzberger/.

Kessler, R. C., \& Üstün, T. B. (2004). The world mental health (WMH) survey initiative version of the world health organization (WHO) composite international diagnostic interview (CIDI). International journal of methods in psychiatric research, 13(2), 93-121.

Kant, S., Vertinsky, I., Zheng, B., \& Smith, P. M. (2014). Multi-domain subjective wellbeing of two Canadian First Nations communities. World Development, 64, 140-157.

Mind. O. (2018) Five Ways to Wellbeing, New Economics Foundation, diundung 28 Januari 2020, dari https://www.mind.org.uk/workplace/mental-health-at-work/taking-care-ofyourself/five-ways-to-wellbeing/.

Oldenburg, R. (2007). The character of third places. In Urban design reader (pp. 162-168). Routledge.

Seetharamdoo, R. S. (2019). 5 1⁄2 Ways to Well-Being: A Comprehensive Lifestyle Medicine Prescription to Optimise Your Physchological Health, Prevent Disesase and Live with Vitality and Joy. Goodreads.

Standard, I. S. O., \& ISO, B. (1998). Ergonomics of the thermal environment-Instruments for measuring physical quantities.

Stanley, D. (2014). Health, wellness and illness. Kozier \& Erb's Fundamentals of Nursing Australian Edition, 3, 332.

White, E.T. (1987). Buku Sumber Konsep. Bandung: Intermatra 
